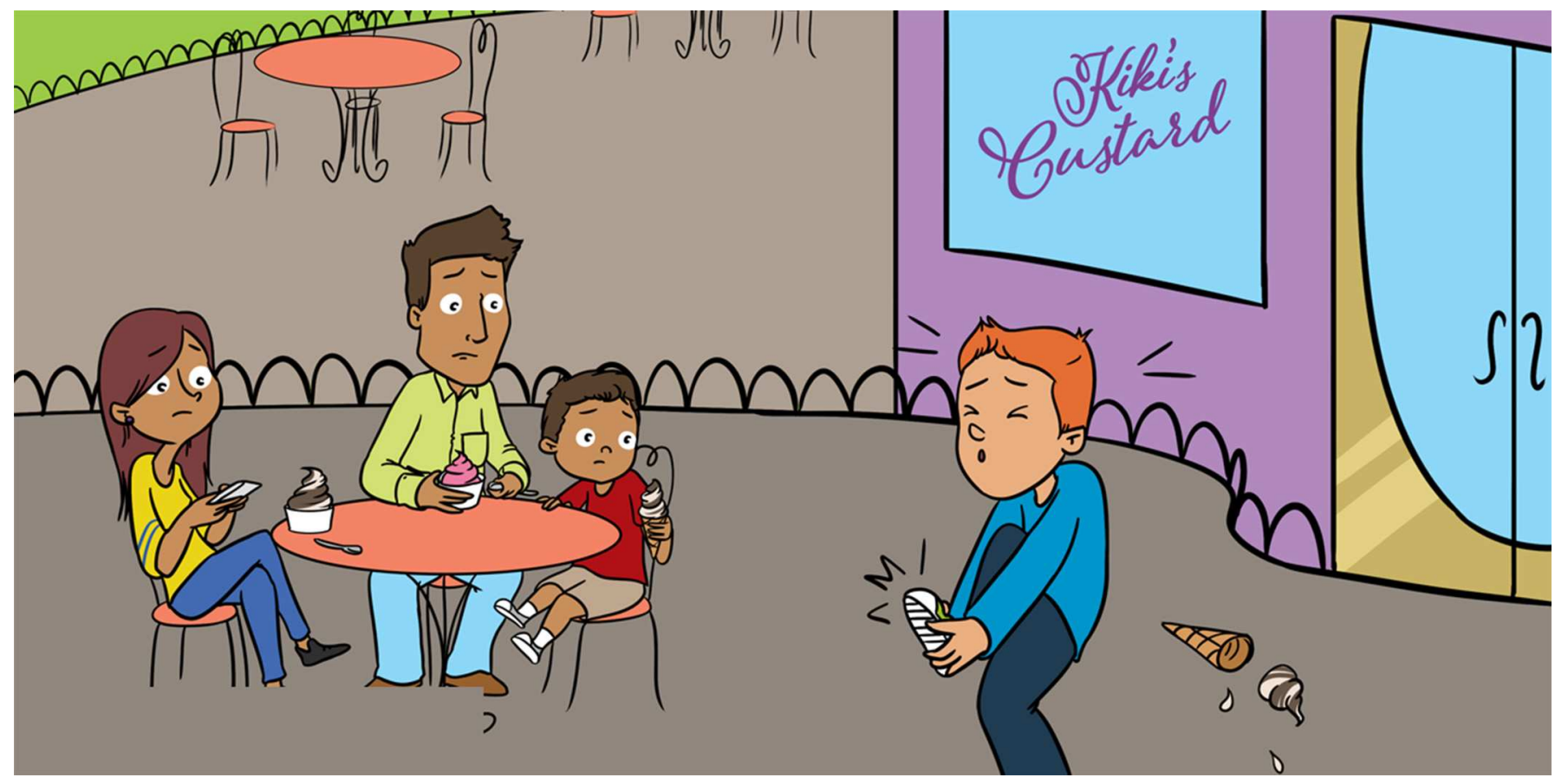

\title{
HOW DO THE BRAINS OF CHILDREN, TEENAGERS, AND ADULTS RESPOND TO OTHERS" PAIN?
}

\section{Jonathan Levy*}

Interdisciplinary Center Herzliya, Herzliya, Israel

YOUNG REVIEWERS:

EXPLORA

SCIENCE

CENTER

AND

CHILDREN'S

MUSEUM

AGE: 8-14
Seeing someone in pain triggers a specific brain response, which is called "pain empathy." In the present article, we examined this brain response in children, teenagers, and adults. We found that children's brain response was of a certain type (called alpha power increase), whereas adults' brain response was of a different type (called alpha power decrease). What we found particularly interesting was that teenagers' brain responses included both types: alpha power increase and alpha power decrease. This suggests that the brain's response to others' pain changes in the course of human development. This study brings up two fascinating questions for future studies: (1) Why do the brains of children, teenagers, and adults respond in very different activation patterns to the pain of others? (2) What is the developmental purpose of the change we see as people get older? 
Figure 1

S1 brain response to others' pain. (A) When seeing someone in pain, the brain can respond by an alpha power increase at $10 \mathrm{~Hz}$ in the S1 area of the brain (red circle) or by an alpha power decrease at $7 \mathrm{~Hz}$ in the S1 area (blue circle). (B) But, when the other is not in pain, the brain does not respond in either of those two response types.

\section{EMPATHY}

The ability to feel or understand the experience of another person.

\section{S1}

Abbreviation for the primary somatosensory cortex, a region in the brain responsible for the sensations (feelings) in the body.

\section{ALPHA RHYTHM}

Brain electrical activity following a rhythmic (i.e., oscillatory) pattern between 7 and $13 \mathrm{~Hz}$ (for instance, $1 \mathrm{~Hz}$ means once per second, whereas $7 \mathrm{~Hz}$ means eight times per second).

\section{NEURON}

The brain consists of cells (i.e., a basic structural unit), and neurons are the cells which enable communication and activity to occur inside the brain.
A Two types of brain response to other's pain

\section{Person in pain}

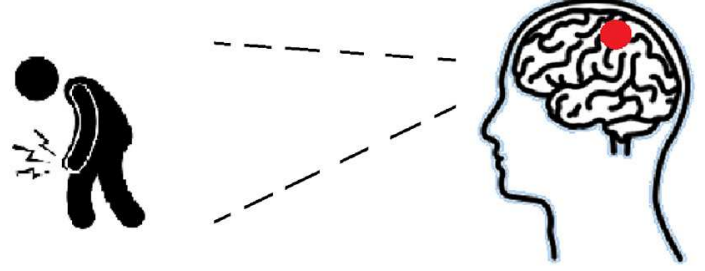

or

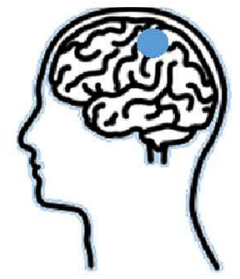

B

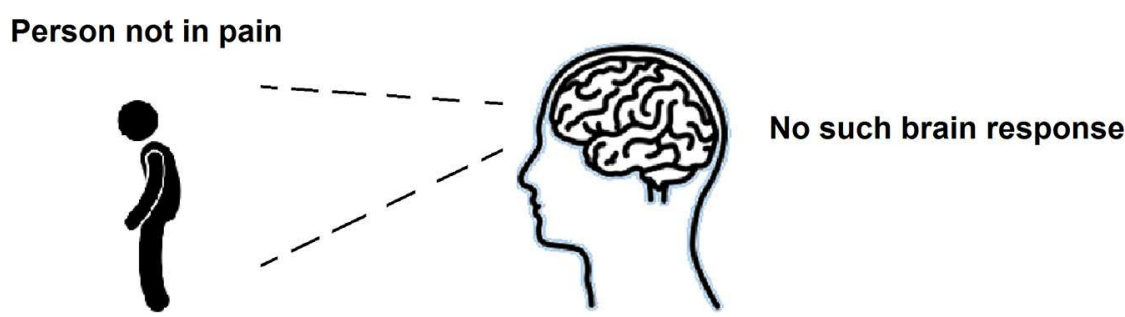

Figure 1

\section{BRAIN RESPONSE TO PAIN: THE ALPHA BRAIN RHYTHM}

In our previous article in Frontiers for Young Minds [1], we talked about the brain response to the pain of others (also called "pain empathy") and showed that it can be measured in the brains of teenagers. We showed that a response to the pain of others can be measured in a brain area that scientists call S1 [2]. S1 can be seen in Figure 1A (red or blue circles in the brain cartoon). What scientists find intriguing is that S1 is activated both in response to the pain of others, and also in response to feeling your own pain. To put it in other words, when you see someone in pain, your brain activates as if you yourself were in pain. This is why it may feel painful when you see someone else in pain.

Many research experiments have studied the brain response to others' pain. One way to look at the brain response to other's pain is to examine something called the alpha rhythm. The brain activates its cells (called neurons) in certain rhythms, and the alpha rhythm is approximately in the frequency between 7 and $13 \mathrm{~Hz}$. The neurons talk to each other so that we can think, feel and make sense of the world around us. They do so by sending electric signals to each other. Some of these signals follow a rhythmic (i.e., oscillatory). For instance, activity at $10 \mathrm{~Hz}$ (in the range of the alpha rhythm) means that activity repeats 10 times in each second. The electric activity creates very weak magnetic fields. The alpha rhythm, as well as other types of brain activity, can be measured by a machine called MEG. MEG measures magnetic fields so it can pick up brain activity, such as the alpha rhythm. In response to certain situations, the alpha rhythm can either increase (called alpha power increase) or decrease (called alpha 
MEG

Abbreviation for magnetoencephalography, which is a machine that can map brain activity. It records the small magnetic fields produced by the electrical currents occurring naturally in the brain.

\section{ALPHA INCREASE}

The instance when the intensity (i.e., power) of the alpha rhythm increases.

\section{ALPHA DECREASE}

The instance when the intensity (i.e., power) of the alpha rhythm decreases. power decrease) or stay the same [3]. An alpha power increase means that more neurons activate in the alpha rhythm, and a decrease in power means that less neurons do so.

The increase or the decrease in power is always in comparison to a baseline situation. For instance, when we say that alpha power decreases when someone is awake, this would mean that power is lower than compared to when that person is asleep-asleep would be the baseline. Another example: if alpha power decreases when we see someone in pain, this would mean that alpha power is lower compared with when we see someone who is not in pain. In this example, the brain response to the person who is not in pain would be the baseline. Previous studies showed that the decrease and the increase in alpha power both have different functions. However, scientists have been working on figuring out the exact meaning of these changes in alpha power [3]. So, looking at the alpha rhythm is informative for better understanding how the brain operates in different contexts. Figure $1 \mathrm{~A}$ shows that, when seeing someone in pain, the brain can respond by alpha power increase (red circle) or by alpha power decrease (blue circle). But when the other is not in pain (Figure 1B), the brain does not respond with either of the two activation types.

\section{WHAT DID WE CHECK AND WHAT DID WE FIND?}

In the present study, we studied the brain response to others' pain in children, teenagers and adults. We invited 85 children, 80 teenagers, and 44 adults to participate in our study. We showed participants photos of real people in pain, the same way we did in our previous study published in Frontiers for Young Minds [1]. In Figure 1A, we used cartoon drawings to show examples of painful and non-painful pictures. In the real experiment, we used actual photos. While they were looking at the photos, participants' brains were examined using the MEG helmet, as described in the previous section [4].

After the experiment, we looked at the MEG brain measurements: We were astounded to find very different activation patterns in the brains of children, teenagers, and adults! Figure 2A shows the activation types in S1: the red circle in the brain shows alpha power increase, and the blue circle in the brain shows alpha power decrease. The increase in alpha power means that when the study participants watched someone in pain, the alpha rhythm was stronger compared with when they watched someone who was not in pain. By contrast, the decrease in alpha power means that when the participants watched someone in pain, the alpha rhythm was weaker compared with when they watched someone who was not in pain. The graph in Figure 2B shows the brain response in children, teenagers, and adults. Children showed alpha power increase, teenagers showed both alpha power increase and alpha power decrease, and adults showed alpha power decrease. It is very interesting to notice that teenagers show both activation 
Figure 2

Brain response to others' pain in children, teenagers, and adults. (A) As in Figure 1, the circles indicate the S1 area of the brain, with red representing alpha power increase and blue representing alpha power decrease. (B) The brain responses to looking at images of others in pain, in children, teenagers and adults. Children showed only alpha power increase, teenagers showed both alpha power increase and alpha power decrease, and adults showed only alpha power decrease.

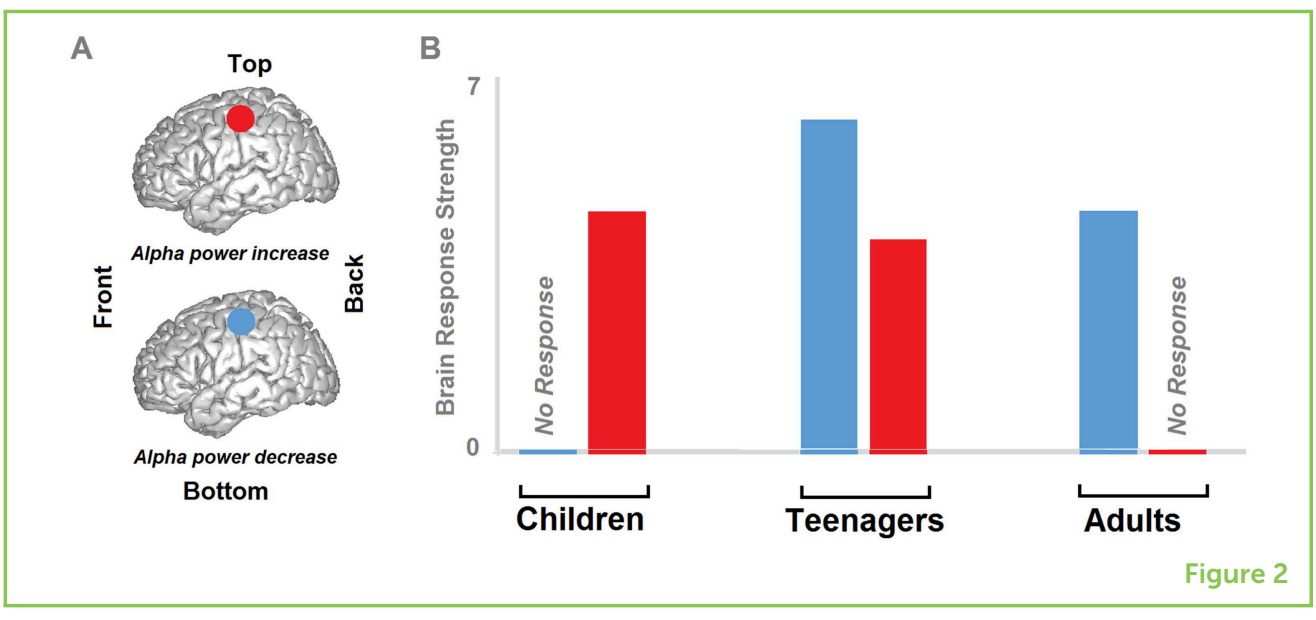

types, the one usually seen in children and the one usually seen in adults.

\section{WHAT DOES DO OUR FINDINGS MEAN?}

Why do teenagers show these two activation types at the same time? Well, it is because there are different forms of alpha activity (low alpha frequency at $\sim 7 \mathrm{~Hz}$ and high alpha frequency at $\sim 10 \mathrm{~Hz}$ ). We found that, for the teenagers, the number of neurons firing at a $7 \mathrm{~Hz}$ rhythm (or power) decreases (like in the adults) and the number of neurons firing (or power) at a $10 \mathrm{~Hz}$ frequency increases (like in the children). This suggests that we might be seeing a developmental process: teenagers' brain responses seem to be transforming from the brain responses of children to those of adults. Of course, more studies are needed in the future to make sure that this is true and to see whether this process is gradual or happens at a specific age.

At the end of our experiment, we also asked the child and adult participants to rate how painful it was for them to look at the painful pictures in the experiment. Most participants said that looking the pictures was very painful, and we did not find that this rating differed between adults and children. This means that we cannot explain our brain activation pattern results simply by saying that either children or adults found the pictures more painful to look at.

\section{WHAT IS NEXT?}

What could our findings mean? Well, to be honest, we do not really know. One possible interpretation that we propose is that adults naturally activate the S1 area of the brain when responding to the pain of others. By contrast, children might not activate S1, and perhaps even inhibit its natural activation. More studies will be needed in the future to better understand this potential discovery. In science, when 
you discover something, it may take many years until future studies clarify the meaning of the discovery.

We are currently in the process of planning new experiments, which could clarify our discovery. First, we plan to study whether our observation of brain differences in children and adults observing others in pain can be detected by other brain imaging tools besides the MEG helmet. Other brain imaging tools can show us similar yet different processes in the brain, and so it is important to repeat our experiment using these alternative tools. Second, we would like to collect other forms of self-reports on emotions and on behavior, such as the willingness to help the people in pain, or whether they recall having experienced a similar situation in the past We hope that, by comparing this kind of information to the brain activity information that we measure, we can eventually understand the remarkable differences that we found between children, teenagers, and adults. One last point: If this study made you curious about how you, as a child, respond to others' pain, and why the way you respond may be different than the way adults respond-you are more than welcome to contact me (see below in the section "About the Author"). I would be very happy to listen to your ideas and thoughts. Your ideas might eventually lead to new experiments on this topic!

\section{ACKNOWLEDGMENTS}

I wish to thank the researchers with whom I worked on this project: Ruth Feldman, Maayan Pratt, and Abraham Goldstein. The icons on the figure were taken from thenounproject.com and slightly modified; these are under CC attribution and include the following: "Knee Pain" and "Man standing side view" icons by Gan Khoon Lay, and "Human Brain" icon by Laymik.

\section{ORIGINAL SOURCE ARTICLE}

Levy, J., Goldstein, A., Pratt, M., and Feldman, R. 2018. Maturation of pain empathy from child to adult shifts from single to multiple neural rhythms to support interoceptive representations. Sci. Rep. 8:1810. doi: $10.1038 / s 41598-018-19810-3$

\section{REFERENCES}

1. Levy, J., and Feldman, R. 2017. Can teenagers feel the pain of others? Peeking into the teenage brain to find empathy. Front Young Minds 5:1-8. doi: 10.3389/frym.2017.00059

2. Lamm, C., Decety, J., and Singer, T. 2011. Meta-analytic evidence for common and distinct neural networks associated with directly experienced pain and empathy for pain. Neuroimage 54:2492-502. doi: 10.1016/j.neuroimage.2010. 10.014 
3. Jensen, O., and Mazaheri, A. 2010. Shaping functional architecture by oscillatory alpha activity: gating by inhibition. Front. Hum. Neurosci. 4:186. doi: 10.3389/fnhum.2010.00186

4. Brock, J., and Sowman, P. 2014. Meg for kids: listening to your brain with super-cool SQUIDs. Front Young Minds 2:1-4. doi: 10.3389/frym.2014.00010

SUBMITTED: 06 December 2018; ACCEPTED: 27 May 2019; PUBLISHED ONLINE: 11 June 2019.

EDITED BY: Kathleen Y. Haaland, University of New Mexico, United States

CITATION: Levy J (2019) How Do the Brains of Children, Teenagers, and Adults Respond to Others' Pain? Front. Young Minds 7:82. doi: 10.3389/frym.2019.00082

CONFLICT OF INTEREST STATEMENT: The author declares that the research was conducted in the absence of any commercial or financial relationships that could be construed as a potential conflict of interest.

COPYRIGHT () 2019 Levy. This is an open-access article distributed under the terms of the Creative Commons Attribution License (CC BY). The use, distribution or reproduction in other forums is permitted, provided the original author(s) and the copyright owner(s) are credited and that the original publication in this journal is cited, in accordance with accepted academic practice. No use, distribution or reproduction is permitted which does not comply with these terms.

\section{YOUNG REVIEWERS}

\section{EXPLORA SCIENCE CENTER AND CHILDREN'S MUSEUM, AGE: 8-14}

The Explora Young Minds reviewers are a group of science enthusiasts working with museum educators and mentors from the University of New Mexico. We enjoy learning about the brain through the articles. We also enjoy asking questions and making suggestions to help the scientists make their work more understandable for everyone! We were helped by our Science Mentor, John Elias, who is working to complete his post-doctoral fellowship in the field of pediatric neuropsychology.

\section{AUTHOR}

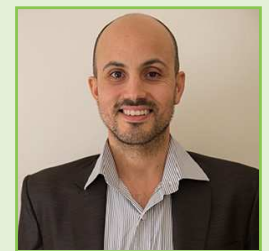

\section{JONATHAN LEVY}

I love to study our inner world and our social behavior from the perspective of the brain. Besides that, I mainly love walking in nature, mind wandering in nature, talking to people, and interacting with my kids. *yoniilevy@gmail.com 